\title{
A juventude da periferia na escola: o que é problema?
}

\author{
Los jóvenes de los suburbios en la escuela: ¿Cuál es problema? \\ The youth of the suburbs at school: what is problem?
}

\author{
Lic. Michele Lopes Leguiça ${ }^{1}$ \\ Dra. Alinne de Lima Bonetti ${ }^{2}$
}

\begin{abstract}
Resumo
Este artigo objetivou problematizar a noção de "aluna/o-problema", inicialmente definida por critérios como baixo rendimento escolar, indisciplina, recuperação paralela, com vistas a compreender como tal noção é apropriada e resignificada pelos diferentes sujeitos da comunidade escolar e como opera na construção de identidades das/os estudantes Para tanto, utilizou-se a metodologia de pesquisa qualitativa, a partir da abordagem de Estudo de Caso, entre estudantes do $7^{\circ}$ ano de uma Escola Municipal de um bairro periférico da cidade de Uruguaiana/RS. Concluiu-se que a noção de "aluna/o- problema" guarda uma complexidade de sentidos e aponta para o encontro entre universos simbólicos e visões de mundo distintos no espaço escolar, constituídos por marcadores sociais da diferença que se interseccionam, tais como gênero, raça, classe. Ao descortinar esses significados implícitos, esta pesquisa buscou contribuir para o repensar das alteridades no contexto escolar e das relações de ensinagem e aprendizagem. Levando-se em conta que a construção das identidades sociais é um processo relacional, dinâmico e transitório, foi relevante problematizar os diferentes significados atribuídos à noção de problema, de forma a produzir conhecimento sobre essa realidade e, assim, contribuir para a sua transformação.
\end{abstract}

Palavras-Chave: aluna/o-problema; identidade; indisciplina.

\section{Resumen}

Este artículo pretende discutir la noción de "estudiante problema", inicialmente definido por criterios como el rendimiento escolar bajo, indisciplina, paralelo recuperación, entendiendo cómo tal noción es apropiada y resignificada por los diferentes temas de la comunidad escolar y cómo funciona en la construcción de identidades de estudiantes por tanto, se utilizó la metodología de la investigación cualitativa, desde el enfoque de estudio de caso entre estudiantes de $7^{\circ}$ grado de un pasillo de la escuela de un barrio periférico de la ciudad de Uruguaiana/RS. Se concluye que la noción de "estudiante-problema" guardan una complejidad de significados y puntos de encuentro entre universos simbólicos y visiones del mundo distintas en el espacio escolar, que consiste en marcadores sociales de diferencia que se intersecan, como género, raza, clase. Para descubrir estos significados implícitos, este estudio buscó contribuir al replanteamiento de la alteridad en el contexto escolar y las relaciones de aprendizaje y el aprendizaje. Teniendo en cuenta que la construcción de las identidades sociales es que un proceso relacional, dinámico y transitorio, era relevante para discutir los diferentes significados asignados a la noción de la materia, con el fin de producir conocimiento sobre esta realidad y así contribuir a su transformación.

Palabras clave: estudiante problema; identidade; indisciplina.

\begin{abstract}
This article aimed to discuss the notion of "student/the-problem", initially defined by criteria such as low school performance, indiscipline, parallel recovery, in order to understand how such a notion is appropriate and
\end{abstract}

\footnotetext{
${ }^{1}$ Licenciada em Educação Especial; Universidade Federal do Pampa - Unipampa; Uruguaiana, Rio Grande do Sul, Brasil; micheleleguica@ hotmail.com.

${ }^{2}$ Doutora em Ciências Sociais; Universidade Federal do Pampa - Unipampa; Uruguaiana, Rio Grande do Sul, Brasil; alinnebonetti@unipampa.edu.br
} 
resignificada by the different subjects of the school community and how it operates in the construction of identities of/students for both, we used the methodology of qualitative research, from the case study approach between 7th grade students of a school Hall of a peripheral district of the city of Uruguaiana/RS. It was concluded that the notion of "student/the-problem" guard a complexity of meanings and points to the encounter between symbolic universes and distinct world views in the school space, consisting of social markers of difference that intersect, such as gender, race, class. To uncover these implicit meanings, this study sought to contribute to the rethink of otherness in the school context and relations of learning and learning. Taking into account that the construction of social identities is a relational process, dynamic and transient, was relevant to discuss the different meanings assigned to the notion of matter, in order to produce knowledge about this reality and thus contribute to its transformation.

Key words: problem-student; undiscipline; identity.

\section{Introdução}

Sendo todas as coisas causadas e causadoras, ajudadas ou ajudantes, mediatas e imediatas, e sustentando-se todas por um elo natural e insensível que une as mais distantes e as mais diferentes, considero ser impossível conhecer as partes sem conhecer o todo, tampouco conhecer o todo sem conhecer parcialmente as partes. (PASCAL, 1976, apud MORIN, 2011:35)

Este artigo é parte da experiência de pesquisa de projeto homônimo que aconteceu de agosto de 2015 a janeiro 2016, que objetiva compreender a construção da identidade de estudantes considerados "problema" pela comunidade escolar (segundo os critérios baixo rendimento escolar, indisciplina, recuperação paralela), bem como a influência dos marcadores sociais da diferença (tais como gênero, raça/etnia e pertencimento social) nesta construção. Como metodologia, utilizou-se a pesquisa qualitativa, a partir da abordagem de Estudo de Caso, com técnicas e recursos auxiliares de pesquisa qualitativa, tais como: observação participante, entrevistas semidirigidas e registros em diários de campo (doravante DC); (FLICK, 2009) entre estudantes do $7^{\circ}$ ano, de 12 a 17 anos, as/os alunas/os da turma $7 \mathrm{X}$ na sua maioria, para não dizer que todas/os possuem as características buscadas na pesquisa, turma esta indicada pelo Serviço de Orientação Escolar, Coordenação escolar, o recorte empírico se deu na escola de Ensino Fundamental Monumento ${ }^{3}$, situada em bairro periférico da cidade de Uruguaiana/RS. Na apresentação deste recorte, buscou-se complexificar a noção de "problema", tomando como referencial de análise a perspectiva das/os estudantes, interlocutoras/es desta investigação. Por meio dos dados oriundos da observação e do convívio no espaço escolar, buscou-se problematizar o quanto a educação naquele espaço por muitas vezes naufraga e não surgem possibilidades de transformação. $\mathrm{O}$ processo educacional tornou-se uma ilha, deixando à deriva a comunidade escolar, educadoras/educadores,

\footnotetext{
${ }^{3}$ Os nomes, da escola onde foi realizada a pesquisa, bem como das/os interlocutoras/es desta pesquisa foram trocados de maneira a preservar a identidade e resguardar o anonimato, seguindo preceitos éticos que baseiam a pesquisa científica.
} 

e-ISSN 2016/Atual: 2525-7870 | e-ISSN 2015/2016: 2447-018X

estudantes e responsáveis, tensionadas/os por vários fatores, marcadores sociais da diferença que atuam, se articulam, reforçando a distância e o estranhamento. Nesta tela vou me deter nas relações dentro da sala de aula, entre eles e elas, as/os dissidentes. Conhecê-las/os nas suas microrrelações, suas práticas, gostos, dia-a-dia, para entender as variantes e as relações múltiplas que possuem, pois cada um dentro da sala traz consigo um universo. Para tanto, este artigo busca responder questões em torno de como se autoidentificam como: "a identidade é de problema?", “e a aprendizagem é um problema?”, “a família é um problema?" que aprofundam as definições sobre a noção de problema, agora do ponto de vista do corpo discente. Esses outros sentidos nos ajudam a complexificar aqueles apresentados pelo corpo docente. Acreditando que este olhar mais intimista possa nos trazer subsídios para o repensar o conceito "aluna/o- problema", pensar para uma dissidência, provocada por choques de universos diferentes, que estes elementos venham ao encontro da melhoria e excelência na educação para todas/os.

\section{Como se (re)conhecem: a identidade é de problema?}

Num momento da pesquisa ${ }^{4}$ fico sozinha com eles, que vem em minha direção e me enchem de perguntas: o que tu fazes aqui? O que achaste da turma? - Respondo um lacônico, Tranquilo...Bruna ${ }^{5}$ ri e questiona: Tranquilo? Dizem que somos os piores da escola! (DC 02/09/2015).

Eles/as tem conhecimento do rótulo que possuem na escola, sendo estes os "piores". Outro ponto de choque entre o corpo docente e discente é o poder de controle e préjulgamento. Uma manhã foi tensionada pela busca por livros que não foram encontrados, como registrei em meu Diário de Campo:

Recolhem os livros e os trabalhos, na contagem faltaram dois livros. O professor pede para que todos vejam debaixo de suas mesas e que olhem dentro da mochila, pois podem ter guardado por engano. Começa um tumulto e comentários entre a turma: é, tem que ser muito chinelo para roubar livros. Bando de ladrão! O professor pede que Cristiano olhe sua mochila, ao que reage irritadamente, virando todo material no chão. Abre a mochila, mostra-a e diz: não tem mais nada aí!(DC 11/09/2015).

\footnotetext{
${ }^{4}$ Reservei o uso do itálico para demarcar os elementos textuais oriundos dos meus dados de campo e também para aqueles substantivos de língua estrangeira, como a norma da Língua Portuguesa.

${ }^{5}$ Bruna é um jovem de 13 anos, autodeclarada negra, vive com a mãe, irmão maior de idade e irmã de 2 anos; na escola seu resultado final é de $98 \%$ de freqüência, aprovada em todas as matérias, sua média menor é 73 Língua Portuguesa, sendo uma das alunas que possui maiores notas da turma, considerada aluna padrão.

${ }^{6}$ Cristiano é um jovem de 14 anos, vive com mãe/madrasta, e duas irmãs menores, na escola é considerado o "pior" aluno, é repetente do $7^{\circ}$ ano e já havia sido transferido para outra escola, que a transferiu novamente na metade do ano.
} 

e-ISSN 2016/Atual: 2525-7870 | e-ISSN 2015/2016: 2447-018X

Cabe lembrar que realmente foi feita a contagem e faltavam dois livros, no entanto o docente agiu informado pelas pré-noções, buscando entre o grupo, um aluno em específico para que lhe mostrasse a mochila. Cristiano é considerado o pior aluno da turma e não era de se esperar outra atitude dele, senão a de esparramar o material de sua mochila, quando foi solicitado que a revisasse para verificar. Para contrapor, e entender um pouco estas relações entre aluno/a-professor/a, este mesmo aluno assumiu uma atitude de rebeldia em meio a uma avaliação, na aula de outra professora. Vejamos:

A professora chama a atenção de Cristiano sobre estar riscando na mesa, ao que responde: minha caneta não está funcionando. Ela pede a ele que se ajeite. Ele pega, então, sua folha de rascunho, debruça-se sobre ela e continua riscando, agora sobre a folha. A professora começa a recolher a prova e pede que todas/os se mantenham em silêncio. Quando chega a fez de Cristiano chama novamente sua atenção: você não colocou seu nome na prova? Cristiano responde novamente: falei que minha caneta não está funcionando. A professora pede, então, uma caneta para que ele assine e sob sua orientação, ele assina e coloca a data (DC 15/09/2015).

Esta passagem é exemplar para problematizarmos como se lida com o "problema". Analisemos a situação: um aluno, no final do segundo trimestre, se mantém debruçado sobre a classe no momento da aplicação da prova, e em alguns momentos tentando rabiscar com uma caneta que não funcionava. A atitude foi, aparentemente, de descrédito e somente na hora de recolher a avaliação, a docente conseguiu uma nova caneta, para que ele colocasse a data e assinasse seu nome completo e nada mais. Não percebi uma única tentativa de apelo ou questionamento sobre a atitude de não fazer a prova ou ele de ter sido chamado para orientação, para juntos buscar formas de reavaliar ou recuperar este aluno. Presenciei situações em que, por muito menos, o vi ser encaminhado ao SOE sob a justificativa de ter bagunçado ou respondido ironicamente aos/às educadores/as. Longe de avaliar a atitude da docente, o que é relevante aqui é perceber os mecanismos insidiosos do imaginário acerca do "aluna/o-problema" operando na relação docente/escola-discente. Teria a escola, desistido dele? O rótulo turma dos piores acaba por agir em diferentes momentos, trazendo resultados nefastos para a própria subjetividade destas/destes discentes. Tal rótulo torna a turma conhecida na escola e admirada, por um lado e, depreciada, de outro. Resultando no descrédito de que possam ser os melhores.

Numa ocasião, uma escola de Cursos técnicos para adolescentes distribuiu vale descontos para a turma. O slogan da propaganda era de que apenas os melhores foram escolhidos para ganhar o desconto. Empolgados começam a pesquisar se alguém, na turma, havia recebido. 
Começam a perguntar quem vai fazer os cursos, daqueles caras. "Somos melhores", lembra Luciana ${ }^{7}$. No panfleto diz que os melhores alunos receberiam. Quem recebeu?Paulo? Mario?Pedro? ${ }^{8}$ Ih, vocês são os melhores da turma? Maria ${ }^{9}$ coloca que também recebeu, Pedro ri e diz: "somos os melhores!". Observando a movimentação, penso que todas/os acabaram recebendo o panfleto. Maria, desconfiada, alerta: tem uns aí que receberam que não sei não! (DC 04/11/2015)

Apenas acreditar na educação como ponto transformador é uma ilusão, quando esta não é pensada e repensada levando em conta todos/as seus/suas atores/atrizes, quando um/a estudante não acredita mais em si, acredita não ter capacidade de estar naquele lugar, passa-se a questionar se, de fato a educação é transformadora. De certa forma, sim, pois transforma sonhos em pesadelos, quando acredita que seus/suas estudantes são problemas sociais, e não reconhecem sua parcela na construção deste público.

Outro aspecto importante na reflexão sobre identidade de "aluna/o- problema" está no autor reconhecimento. Ao serem interpeladas/os sobre o que entendem pela expressão "aluna/o- problema" ou se já tiveram contato com algum/alguma, recebi a indicação de Cristiano. Vejamos: Aluno problema, tipo um aluno que é problema? Já. O Cristiano, aquele aluno que não quer nada com nada, para ele a escola é uma brincadeira, era bem o que aquele aluno da nossa aula ali fazia. (Cintia ${ }^{10}$, DC 26/11/2015). Outros colegas continuam a citá-lo: Um aluno que é problema, que incomoda, o Cristiano. (Ricardo ${ }^{11}$, DC 25/11/2015); Aluno-problema? Já, o Cristiano é um (Paulo, DC 01/12/2015). Cristiano assume que é um problema. Várias vezes, significa “eu”, tem meu primo que está chegando [para estudar na escola] e já tá rateado de pá (Cristiano, DC 11/01/2016). Mas essa autoidentificação não se restringe apenas ao Cristiano. Há outro estudante que acaba por se assumir também como parte do problema da turma 7X: Mário sacode a cabeça e diz: bagunça, eu! (Mario, DC 25/11/2015).

Já no que diz respeito à noção de indisciplina, as definições seguem parecidas com as dos docentes. Vejamos: Eu entendo que é o aluno que não sabe fazer os temas, que não se

\footnotetext{
${ }^{7}$ Luciana é uma jovem de 13 anos, mora com pai, mãe e irmã, na escola é considerada a melhor aluna e representante discente da turma $7 X$, têm $96,9 \%$ de frequiência e sua nota mais baixa é 76 em matemática.

${ }^{8}$ Paulo, Mario e Pedro são jovens de 15, 16, 14 anos de idade, este trio geralmente esta no centro de várias cenas de bagunça na sala de aula, os três já foram reprovados em algum momento da sua vida escolar.

${ }^{9}$ Maria é uma jovem de 12 anos, é adotada, mora com pai e mãe e tem dois irmãos maiores de idade, na escola é considerada uma menina inquieta e que já se envolveu em brigas anteriormente.

${ }^{10}$ Cintia é uma jovem de 13 anos, diz não ter pai, e ter sido criada apenas pela mãe, mora com a mãe, irmão e cunhada, na escola é uma menina calma, tem $95,4 \%$ de freqüência e sua nota mais baixa é 70 em matemática.

${ }^{11}$ Ricardo é um jovem de 13 anos, atualmente esta passando uma temporada com os avós, mas afirma que mora com a mãe e mais quatro irmãos, não sabe o nome do seu pai, na escola é um jovem ativo, um pouco inquieto, participativo, tem 93,3\% de frequiência e sua nota mais baixa é 61 em Língua Portuguesa.
} 

e-ISSN 2016/Atual: 2525-7870 | e-ISSN 2015/2016: 2447-018X

esforça. (Ana ${ }^{12}$, DC 02/12/2015); É uma pessoa que não tem disciplina, que não tem educação com as pessoas, respeito, aqui na escola tem muita indisciplina, os pais não têm uma rédea. (Luciana, DC 24/11/2015); Indisciplina é ser indisciplinado na escola, na sala de aula, não respeitar regras da escola. (Pedro, DC 25/11/2015). E exemplificam com algumas situações recorrentes: (...) bolinhas de papel, estas coisas sabe? Quando se juntam de soquinho... Isso acontece bastante. Sempre vão para a orientação por causa disso. (Bruna, DC 24/11/2015); Eu acho que foi quando minha colega não quis fazer uma prova pra mim; é indisciplina também. (Cintia, DC 26/11/2015); Tipo desrespeitar regras na sala de aula, tipo assim, o professor manda alguma coisa e tu desobedece. (Pedro, DC 25/11/2015).

As suas reflexões e falas sobre problema e indisciplina convergem para as definições do corpo docente. Há ao que parece, uma apropriação e um conhecimento dos parâmetros reconhecidos de bom comportamento. Assim como há, também, um profundo conhecimento dos encaminhamentos que a escola dá para a resolução dos casos: Fazendo ata, chamando os pais, aí ele vai pro conselho, vai pro promotor, depois não sei. (Elias ${ }^{13}$, DC 26/11/2015); Vamos lá pro SOE, avisam os pais, mandam bilhete. (Diogo ${ }^{14}$, DC 26/11/2015); A professora de lá diz que a primeira vez que tu vai lá tu só toma uma advertência, se é a segunda tu toma uma advertência e chama os pais, já na terceira eles é? Eles convidam a se retirar da escola, assim eles fizeram com o Cristiano. (Luciano ${ }^{15}$, DC 25/11/2015)

Importa destacar a prática do ser convidado/a a se retirar. A expulsão não é mais permitida, contudo surgem outros mecanismos utilizados com o mesmo peso, como por exemplo, a transferência, como o foi no caso em questão. A forma como acaba acontecendo, é tomada como uma forma de expulsão, pois independentemente da vontade e da disponibilidade da família e da distância das potenciais escolas destino, a escola entrega o atestado de frequência. Mesmo se o processo não for finalizado, a/o estudante não pode mais retornar à escola. Tendo-se em vista essa situação, é interessante de perceber como Cristiano, o aluno-problema exemplar, elabora o processo de transferência. Ao final das entrevistas, deixava um espaço livre para as suas manifestações, sugerindo que deixassem uma mensagem à escola e aos/às professores/as. Cristiano foi um das/os poucas/os que o utilizaram e o fez

\footnotetext{
${ }^{12}$ Ana é uma jovem de 12 anos, venho transferida no final de ano, devido mudança da família para o Bairro, mora com pai,mãe, seis irmãs/os e o avô, na escola é quieta e calma, tem 100\% de freqüência, e sua nota mais baixa é 6,0 em Língua Portuguesa e Ensino Religioso.

${ }^{13}$ Elias é um jovem de 12 anos, mora com avô e avó tem 4 irmãs/os, na escola Elias é agitado e faz parte da bagunça, tem frequiência de 95,6\% ficando em progressão em duas disciplinas das quais não alcançou média para aprovação, sendo elas: Matemática 53 e Língua Portuguesa 52.

${ }^{14}$ Diogo é um jovem de 14 anos, autodeclarado preto, mora com pai, mãe e irmãs/os que são casados e uma irmã que é menor, na escola é participativo na aula e, participa ativamente das bagunças, tem $88,5 \%$ de frequiência e sua nota menor é 65 em Língua Portuguesa.

${ }^{15}$ Luciano é um jovem de 12 anos mora com mãe, pai e irmã/o, na escola é vice representante discente da turma, comportado e quieto, tem frequiência de $97,4 \%$ e sua nota mais baixa é 63 em Língua Portuguesa.
} 
com a seguinte mensagem: Que eи amo muito eles. Agora eu vou ver se vou ali para Escola Oscar, por que no Monumento não dá mais, não dava por que eu incomodava demais. (Cristiano, DC 11/01/2016).

Neste processo de identificação, mesmo havendo resistências a se enquadrar na definição de problema, reconhecer-se como turma indisciplinada confere a estes sujeitos um outro olhar sobre si, sobre a escola e sobre o próprio processo de ensino-aprendizagem. Vejamos se é nesse processo que se localiza o problema.

\subsection{Será a aprendizagem, um "problema"? As brincadeiras inteligentes}

A observação participante dentro da sala de aula proporcionou-me vivenciar a complexidade das relações que se dão que em muitas vezes são tomadas como complicadores no processo de aprendizagem. Um desses supostos complicadores pode ser identificado no que chamarei, na falta de caracterização melhor, de brincadeiras inteligentes no contexto de sala de aula. Tais brincadeiras, à primeira vista, podem ser tomadas como estopins para a bagunça. No entanto, ao observá-los mais de perto, pode-se perceber como estes/estas estudantes se apropriam dos conteúdos, ressignificando-os, ao mesmo tempo em que subvertem as relações verticais estabelecidas entre o ensino e aprendizagem. Vejamos uma situação observada na aula de Ciências.

O professor elenca as partes do corpo, atribuindo-lhes um número a cada uma e solicita que a turma organize as partes relacionadas: Cabeça (1), Pescoço (2) e assim por diante. Os/as estudantes questionam a ordem do exercício, perguntando várias vezes como deve ser completado. Ele tenta explicar, quando surge outra questão.Um menino comenta "e quando as partes do corpo se encontram? O quadril, por exemplo?" Menina retruca: "cala a boca!" Outra estudante complementa: "vão aprender a lavar as cuecas!" (DC 17/08/2015)

Esta subversão do exercício conduz a aula para algo de interesse da turma. As partes do corpo, elencadas e enumeradas pelo educador permitem que possam trazer para a roda o que naquele instante lhes é pertinente. Podiam ser aclamadas outras partes do corpo, como as mãos, a boca, mas o quadril antes silenciado torna-se o foco da aula, não por acaso. Talvez por ser esta a parte do corpo, continente da sexualidade, que deve ser disciplinada em nome das atitudes adequadas, regrando o conteúdo apenas no biológico. No entanto, a brincadeira subversiva da ordem se dá trazendo para a cena a relação entre os corpos, demonstrando que sabem os pontos que provocam silêncios do/a educador/a e a fragilidade do sistema educacional da escola, que controla os corredores, mas não a imaginação para burlar a vigília 
sobre a regra. Tal disciplinamento pode ser mais fortemente compreendido em relações às brigas que, em geral, envolvem disputas amorosas. Vejamos outra brincadeira.

Na aula de ensino religioso, o telefone da educadora toca por duas vezes. Na segunda, ela atende e começa a conversa e sai da sala; Toca celular da professora, ela pega o aparelho da bolsa e olha, um deles comenta: "parece meu telefone, quer dizer, do meu avô dei pra ele! A professora sorri. O telefone dela toca novamente atende o telefonema, e sai da sala conversando e ouve-se um "Alô, Paula?". A turma imediatamente aproveita a deixa para zoar o colega de nome homônimo: "Paulo é a tua fêmea que tá ligando pra ela!". (DC 09/09/2015).

Sentada no final da sala, fiquei sem entender aqueles comentários e risos referentes ao colega Marcelo. Ao retornar para a sala, a professora tampouco identificou que o foco dos comentários era sua conversa com a "fêmea" do Paulo. Mais uma vez, tinham encontrado uma brecha na barreira do regramento e bagunçaram. Sem serem notadas/os, trazem a linguagem do jogo de trocadilhos diários que praticam entre eles/as, sem que a educadora perceba que ela está envolvida intimamente na brincadeira. Há, uma outra situação, ainda com a professora de ensino religioso, que gostaria de apresentar por considerá-la significativa do ponto de vista da apropriação de códigos culturais, da explicitação das estruturas de desigualdade sociais e da posição destes/as estudantes nestas estruturas.

\begin{abstract}
A atividade era de leitura e reflexão sobre o texto "A Flor e a Borboleta ${ }^{16 " . ~ O ~ t e x t o ~ v e r s a ~}$ sobre uma alegoria acerca do desejo humano, as manifestações do divino e agradecimento às dádivas recebidas. Parece querer ensinar a resignação e a gratidão. Em suma, um sujeito pede a Deus uma flor e uma borboleta e lhe são enviados um cacto e uma lagarta. O sujeito indigna-se, pois seu pedido não fora atendido. Cristiano, mesmo se mantendo agitado e aparentemente sem interesse na aula, se propõe a responder sobre o que entendeu do texto apresentado pela professora: "É como eu, uma vez pedi para Deus uma Hayabusal e ele me deu uma $C G^{18}$ !" A professora balança a cabeça em atitude reprobatória e comenta: "guri idiota". Incomodada com sua colocação, e entendendo como desvio de assunto tratado em sala de aula, pois não vê ligação nenhuma com o texto, passa-lhe um sermão fazendo uma reflexão sobre o tempo que estão colocando fora: "o dia tem 24 horas, na escola ficam apenas 4horas e não se empenham, daqui a dez anos não adianta se arrepender, cada um faz sua história, ninguém faz nada por ninguém, por isso vocês vão receber o que estão plantando hoje: nada, e se contentem com nada então!" Cristiano murmura, "eu durmo 8 horas". (DC 09/09/2015).
\end{abstract}

\footnotetext{
${ }^{16}$ Uma versão desta fábula está disponível no sítio católico Aleteia (http://pt.aleteia.org/2014/08/13/o-pai-o-filho-a-flor-e-aborboleta/, acesso em 06/06/2016)

${ }^{17}$ Trata-se de uma motocicleta da marca Suzuki, avaliada em torno de R\$63.000,00. Segundo o sítio da fabricante, ela é apresentada como uma "máquina combina impulso impactante, maneabilidade incomparável, proporcionando um passeio suave nas ruas da cidade ou estradas. Sob seu design bate o lendário motor da Suzuki Hayabusa. A sensação do poder da ressonância evoca uma atitude de autoridade ousada, tanto da máquina quanto do piloto. Seu desempenho incomparável proporciona um passeio divertido e alegre em qualquer velocidade, colocando uma barreira nos seus rivais(...)" (Fonte: http://www.suzukimotos.com.br/MOTOCICLETAS/HAYABUSAGSX1300RA.aspx, acesso em 06/06/2016)

${ }_{18}$ Trata-se de uma motocicleta da marca Honda, avaliada em torno de $\mathrm{R} \$ 10.000,00$, comumente utilizada em Uruguaiana pelas/os moto-taxistas.
} 

e-ISSN 2016/Atual: 2525-7870 | e-ISSN 2015/2016: 2447-018X

Pode parecer impertinência do estudante ou até mesmo uma brincadeira infantil, mas lembrar que dormimos oito horas por dia nesta situação traz um indicativo de padronização: todos deveriam dormir oito horas por dia, pelo menos recomenda-se. Nesta mesma direção, todos careceriam estar aproveitando as quatro horas na escola. De forma geral, todos/as deveriam aproveitar este tempo na escola, não somente as/os estudantes, mas também os/as educadores/as, a direção, todos/as que de alguma forma participam do processo de ensinoaprendizagem. A lembrança da padronização recomendável para um sono reparador denota quão ambíguo fora o sermão.

Entre o corpo docente, as brincadeiras são identificadas como agressões ou atitudes inadequadas. Em vista disto, percebi o quanto o discurso do/a aluno/a considerado/a problema é bloqueado pela incompreensão. Neste sentido é importante relembrar Edgar Morin (2011), que nos propõe repensar nossa prática quando nos relacionamos com o que não compreendemos:

A incompreensão produz tanto embrutecimento, quanto este produz incompreensão. A indignação economiza o exame e a análise. Como disse Clément Rosset:A desqualificação por motivos de ordem moral permite evitar qualquer esforço da inteligência do objeto desqualificado de maneira que um juízo moral traduz sempre a recusa de analisar e mesmo a recusa de pensar. (MORIN, 2011:85)

Através dos trocadilhos, das brincadeiras inteligentes, das agressões verbais (segundo o corpo docente), esses/as estudantes escondem as mazelas nas entrelinhas e quem pertence àquele contexto sabe ler, pois a rua é a extensão do pátio de casa, os tios/as moram logo ali, os vizinhos/as fazem parte das práticas de diversão, o jogo de bola no campinho ou no terreno baldio, andando a cavalo, as caminhadas com os amigos/as pela vila, a ida ao cyber, comprar o lanche no bolicho antes de ir para a escola.

A escola não reconhece este sujeito como alguém interrelacional e suas várias relações sociais que a prática do dia a dia, exige, ensina, cobra, modifica, criando todo um contexto, uma rede que envolve a escola, que vai para a sala de aula, mesmo com os portões fechados, não há como impedir que "sinapses sociais" venham a ocorrer dentro e fora da escola e viceversa.

\subsection{A família é o "problema"?}

Nesta pesquisa, a família várias vezes foi articulada como ponto de produção de problemas e sua imputada desestruturação, de acordo com as/os docentes, acabam por refletir dentro da sala de aula. No entanto, tomar a família nuclear como o parâmetro acaba por não 

e-ISSN 2016/Atual: 2525-7870 | e-ISSN 2015/2016: 2447-018X

abranger outras formas de organização familiar, assim como a escola como extensão destas múltiplas famílias. Para nos ajudar a compreender as características da multiplicidade de formas de família entre as camadas urbanas de baixa renda, Claudia Fonseca (1995) aponta:

(...) a prática de circulação de crianças como uma estrutura física da organização de parentesco em grupos brasileiros de baixa renda, nossas atenções se deslocam de um "problema social" para um processo social, e nosso enfoque analítico muda "o de colapso de valores tradicionais" para formas alternativas de organização vinculada a uma cultura urbana. (FONSECA, 1995:15)

Ao contarem sobre as suas famílias e sobre o que fazem quando não estão na escola e nos seus finais de semana, pode-se perceber organizações familiares alternativas ao padrão tradicional nuclear. Elias, por exemplo, mora com os avós e, aos finais de semana vai para o campo jogar bola e, no domingo, vai para [a casa de] sua mãe. (Elias, DC 26/11/2015). Já Diogo afirma que em alguns sábados fica em frente de casa, na rua, brincando com suas parcerias. Tem vezes que vai à casa das suas irmãs e, de vez em quando, fica em casa. (Diogo, DC 26/11/2015). Conforme já apontando anteriormente, há dois entre as/os estudantes que afirmaram não terem pai, não os conhecem e sequer sabem seus nomes. Foram criados apenas pela mãe e irmãs/os. Outro aspecto a ser destacado é que me suas falas comentam da participação, tanto no cuidado da casa, quanto na ajuda com trabalho remunerado, como é o caso de Ana: é bastante agitado, eu vou lá numa mulher lá, que eu não trabalho eu cuido de uma criancinha, ai tenho só que levar pra creche todos os dias. (Ana, DC 02/12/2015). Andressa ${ }^{19}$ mora com o pai e a irmão e tem várias responsabilidades: $E u$ venho pro colégio e depois eu chego em casa e faço o serviço de casa e de noite eu fico com meu namorado, só! (Andressa, DC 01/12/2015). Já Pedro, após a aula, à tarde, vai trabalhar numa oficina. (Pedro, DC 25/11/2015).

Estes relatos apontam para experiências de vida particulares, próprias de um ethos específico, que podem ser compreendidas na chave proposta por Claudia Fonseca (1989):

\footnotetext{
(...) no Brasil, os grupos populares tenham desenvolvido normas familiares distintas das dos grupos dominantes. Se, por um lado este fato parece óbvio, por outro, ele arrisca ser obscurecido pela grande atenção dada atualmente, em pesquisas sobre a evolução da família no Brasil, a influência da higienização, do ideal do indivíduo, e da privacidade (em suma, os valores da família burguesa). Sugiro que esses valores não conseguem se impor sem condições materiais apropriadas e, portanto, que uma boa parte da população brasileira, talvez a maior parte, não seguiu este trilho". ( FONSECA, 1989: 125)
}

\footnotetext{
${ }^{19}$ Andressa é uma Jovem de 13 anos, mora com pai e irmão, na escola é quieta e envergonhada, tem 87,6 \% de frequiência, e sua nota mais baixa é 60 em Língua Portuguesa.
} 
Segundo a autora, em se tratando de grupos populares urbanos, sabe-se

\begin{abstract}
Que a unidade significativa de organização social é a família extensa; que esta família extensa prioriza laços consangüíneos à relação conjugal; e que a circulação de crianças entre diferentes mãe de criação faz historicamente parte da dinâmica familiar destes grupos. (FONSECA, 1995: 22)
\end{abstract}

Lançar este olhar para estas múltiplas configurações familiares nos possibilita tomar as organizações familiares como complexas e plurais, respeitando a história e o contexto de cada um/a. Outra característica relevante do universo investigado diz respeito à proximidade da escola com a história familiar das/os estudantes.

A grande maioria das/os estudantes da turma $7 \mathrm{X}$ afirma que seus/as responsáveis estudaram nesta Escola, seus irmãos/ãs, tios/as tornando este espaço ainda mais familiar ou, como disse Elias, a segunda casa. (Elias, DC 26/11/2015).

Ou ainda, como aponta Cíntia, eu vejo tipo uma casa, assim. De manhã para mim o colégio é minha casa entendeu? Onde tu vens só pra estudar.Mas eu também trago minhas coisas de casa: ser educada, continua a mesma coisa, a mesma coisa que eu sou em casa, a única coisa é que em casa eu não preciso estudar aqui eu estudo, entendeu? (Cintia, DC 26/11/2015).

Nestas reflexões tentei resgatar a juventude da periferia na escola, como estes/as sujeitos se reconhecem, seus processos de autoidentificação, problematizando em que medida a aprendizagem depende de condições oriundas da sua organização familiar ou seria mais uma justificativa escamoteadora dos universos simbólicos em confronto no espaço escolar, poderíamos assumir a dissidência como expressão destes confrontos e não apenas "aluna/oproblema".

\title{
3. Em direção a novas reflexões...
}

Neste sentido, interessa resgatar a contribuição de Stuart Hall (1997) sobre o papel da educação. Segundo ele,

\footnotetext{
O que é a educação senão o processo através do qual a sociedade incute, normas, padrões de valores - em resumo, a "cultura" - na geração seguinte na esperança e expectativa de que, desta forma, guiará, canalizará, influenciará,moldará as ações e as crenças das gerações futuras e conforme os valores e as normas de seus pais e do sistema de valores predominante da sociedade? (p. 40-41).
}

Frente a isto, cabe-se perguntar quais são as normas que estão sendo incutidas? A educação nestas últimas décadas tem se transformado, buscando integração, inclusão, excelência e permanência de todas/os. 
Assim entender com se constroem estas identidades juvenis nestes espaços e o quanto estes são determinantes, proponho à Escola repensar a identidade "aluno/a-, problema"; estes sujeitos sociais que se colocam ou são percebidas/os pela escola como indisciplinadas/os e desregradas/os, sejam percebidas/os como fios condutores de sua realidade, que é dissonante aos valores que estão sendo tomados implicitamente como parâmetro para a realidade escolar, que significativamente fecha os seus portões e silencia-se, acreditando que é neutra enquanto instituição.

Como nos lembra Tomás Tadeu da Silva (2011),

A identidade é sempre uma relação: o que eu sou só se define pelo que não sou; a definição de minha identidade é sempre dependente da identidade do outro. Além disso, a identidade não é uma coisa da natureza; ela é definida num processo de significação que socialmente, lhe seja atribuído um significado (p. 106).

Entender este processo relacional de construção identitária pelo qual estes sujeitos da periferia, reconhecidas/os como "alunos (as)-problema", passam é fundamental para que a Escola cumpra seu papel de inculcação de valores de maneira amplamente democrática.

Mudar esta perspectiva vai além de construção de identidades, vem ao encontro de ser vista/o com parte de um processo que não se dá no vazio, acontecendo por meio de suas relações. E na dinâmica deste processo, que coloca escola-aluno/a-comunidade escolar em uma rede, se faz necessário abrir os portões e assumir a dissidência desta relação que se faz pela diferença, incorporando a possibilidade de identidades alternativas, que são dissidentes de um padrão hegemônico, pautado num universo de valores específicos, tomado como universal.

\section{Referências}

FLICK, Uwe. Introdução á pesquisa qualitativa / Uwe Flick ; tradução Joice Elias Costa. - 3. Ed. - Porto Alegre: Artmed, 2009

FONSECA, Claudia- Caminhos da Adoção. São Paulo: Cortez, 1995.

. Amor e família: vaca sagrada de nossa época? In D’INCAO, Maria Angela e et al. Amor e família no Brasil. São Paulo: Contexto,1989.

HALL, Stuart. A centralidade da cultura: notas sobre as revoluções culturais do nosso tempo. Educação \& Realidade, Porto Alegre, v. 22, nº 2, jul./dez.1997

MORIN, Edgar, 1921- Os sete saberes necessários à educação do futuro/ Edgar Morin; tradução de Catarina Eleonora F. da Silva e Jeanne Sawaya; revisão técnica de Edgard de Assis Carvalho. - 2. Ed.rev. - São Paulo: Cortez; Brasilia, DF: UNESCO, 2011 
RELACult - Revista Latino-Americana de Estudos em Cultura e Sociedade

Revista Latinoamericana de Estudios en Cultura y Sociedad | Latin American Journal of Studies in Culture and Society V. 02, Ed. Especial, dezembro, 2016, p. 507-519| periodicos.claec.org e-ISSN 2016/Atual: 2525-7870 | e-ISSN 2015/2016: 2447-018X

SILVA, Tomaz Tadeu da. Documentos de Identidade. Uma introdução ás teorias do currículo/Tomaz Tadeu. - 3. Reimp - Belo Horizonte: Autentica 2011. 